\title{
STUDY OF MATERNAL AND FETAL OUTCOME AMONG BOOKED AND UNBOOKED PATIENTS AT TERTIARY HOSPITAL
}

\author{
Subedi $S S^{1^{*}}$, Bhansakarya $R^{1}$, Sharma $S K^{1}$
}

\section{Affiliation \\ 1. Department of Obstetrics and Gynecology, Nobel Medical College and Teaching Hospital, Biratnagar, Nepal.}

\section{ARTICLE INFO \\ Received : 12 May, 2020 \\ Accepted : 22 July, 2020 \\ Published : 05 October, 2020}

(C) Authors retain copyright and grant the journal right of first publication with the work simultaneously licensed under Creative Commons Attribution License CC - BY 4.0 that allows others to share the work with an acknowledgment of the work's authorship and initial publication in this journal.

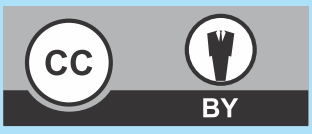

\section{ORA 176}

DOI: https://doi.org/10.3126/bjhs.v5i2.31376

* Corresponding Author

Dr. Shanti Sunuwar Subedi

Associate Professor

Department of Obstetrics and Gynecology

Nobel Medical College and Teaching Hospital, Biratnagar, Nepal Email ID: subedi007@gmail.com

ORCID ID: https://orcid.org/0000-0003-2116-7654

\section{Citation}

Subedi SS, Bhansakarya R, Sharma SK. Study of Maternal and Fetal Outcome among Booked and Unbooked Patients at Tertiary Hospital. BJHS 2020;5(2)12: 1027-1030.

\section{ABSTRACT}

\section{Introduction}

To evaluate the maternal and perinatal outcome in booked and unbooked cases.

\section{Objectives}

To assess the maternal and fetal outcomes in unbooked and booked patients.

\section{Methodology}

This was a cross-sectional comparative study conducted in the Department of Obstetrics and Gynecology from August 2019 to January 2020. Using a convenient sampling technique, 204 samples were taken and cross-sectional study was done.

\section{Results}

There were total 204 cases in this study;102were booked and 102 were unbooked. In this study, 85(83\%) of booked cases were educated up to secondary level as compared to $65(64 \%)$ of unbooked cases. There was no significant difference in Apgar score in 1 and 5 minute between booked and unbooked cases. More babies in the unbooked group were transferred to NICU as compared to the booked group and the difference was significant (9.8\%vs $1.9 \%$ ).

Greater proportion of booked cases had spontaneous vaginal delivery $(81.3 \%$ vs $59.8 \%$ ) and complications like preterm delivery, anemia, preeclampsia/ eclampsia, complicated labor and puerperal sepsis was also less in the booked group.

\section{Conclusions}

The study showed that unbooked mothers and their newborns had higher chance of having complications.

\section{KEYWORDS}

Anaemia, booked mothers, unbooked mothers, maternal outcome, perinatal outcome. 


\section{INTRODUCTION}

Pregnancy even though a physiological phenomenon is a very vulnerable period which can quickly change into a high risk state. There are many complications that can occur during this period; so antenatal care is recommended to prevent or manage these conditions. Antenatal care's aim is to achieve a healthy mother and healthy baby by giving appropriate care and identifying high risk cases. In low income country like Nepal, WHO proposes at least of four antenatal visits with first visit in first trimester to be labelled as "booked" case. ${ }^{1}$ According to 2016 NDHS survey, 69\% of pregnant woman had four ANC visits and pregnancy related mortality rate has dropped to 259 per 100,000 pregnant woman as compared to that of 543 in $1996 .{ }^{2}$

This study aims to compare the difference in socio demographic characteristics as well as maternal and fetal outcome between booked and unbooked cases.

\section{METHODOLOGY}

This was a cross sectional comparative study done in the Department of Obstetrics and Gynecology of Nobel Medical college teaching hospital and research centre Biratnagar, from $1^{\text {st }}$ August 2019 to $31^{\text {st }}$ January 2020 for a duration of 6 months. Sample size was calculated and a total of 204 cases were taken for the study 102 in booked group and 102 in unbooked group. The formula used is

$\mathrm{n}=\mathrm{Z}^{2} \times \mathrm{p} \times \mathrm{q} / \mathrm{e}^{2}$

$\mathrm{n}=$ sample size calculation

$Z=1.96$ at $95 \%$ Confidence Interval

$p=$ prevalence, 0.07

$q=1-p$

e $=$ margin of error, $5 \%$

$\mathrm{n}=102$

The women who have not received four antenatal care visits were categorized as 'unbooked. Information was noted in predesigned proforma. Maternal outcomes measures recorded were anemia, hypertension, diabetes, antepartum hemorrhage, postpartum hemorrhage, obstructed labor, and puerperal sepsis, preterm rupture of membranes, malpresentation in labor, uterine rupture, operative deliveries and their indications. Perinatal outcomes recorded were intrauterine fetal death, stillbirth, low birth weight, Apgar score, NICU admission with their indications and early neonatal death.

The data were entered in SPSS 21. Descriptive statistics i.e. mean and standard deviation were calculated from continuous variables while frequencies and percentages were calculated from categorical variables and level of significance was noted using Chi square and test for parametric variables and Mann Whitney and Wilcoxon for nonparametric variables.

\section{RESULTS}

Total of 204 patients were taken for the study; 102 in each group-booked and unbooked.

The majority of the patients in the unbooked group were younger, less educated and unemployed than the booked cases.

Table 1: Socio demographic profile of unbooked and
booked cases
\begin{tabular}{|l|c|c|}
\hline & $\begin{array}{c}\text { Unbooked } \\
\text { n (\%) }\end{array}$ & $\begin{array}{c}\text { Booked } \\
\text { n (\%) }\end{array}$ \\
\hline Age group (years) & $18(17.6)$ & $5(4.9)$ \\
\hline$<20$ & $78(76.4)$ & $90(88.23)$ \\
\hline $20-35$ & $6(5.88)$ & $7(6.86)$ \\
\hline$\geq 35$ & & \\
\hline Education level & $37(36.27)$ & $17(16.6)$ \\
\hline Illiterate and primary & $38(37.25)$ & $28(27.4)$ \\
\hline Secondary level & $27(26.47)$ & $57(55.8)$ \\
\hline $\begin{array}{l}\text { Higher secondary level } \\
\text { and above }\end{array}$ & & \\
\hline Parity & $20(19.6)$ & $25(24.5)$ \\
\hline 0 & $37(36.27)$ & $45(44.11)$ \\
\hline $1-2$ & $45(44.11)$ & $32(31.3)$ \\
\hline$\geq 3$ & & \\
\hline Occupation & $98(96)$ & $65(63.7)$ \\
\hline Housewife & $4(3.9)$ & $37(36.27)$ \\
\hline Business/ Service & & \\
\hline
\end{tabular}

The mean hemoglobin level in the booked case was $10 \mathrm{gm} \%$ and in the unbooked case was $9.1 \mathrm{gm} \%$ and the difference was not statistically significant. One third of unbooked patients were anemic (38.2\% vs $12.7 \%)$.

Unbooked patients were twice as likely to have cesarean section than booked patients $(29.4 \%$ vs $13.7 \%)(p<0.05)$ and also twice as likely to have instrumental delivery $(10.7 \%$ vs $4.9 \%)(p<0.05)$ (Figure 1)

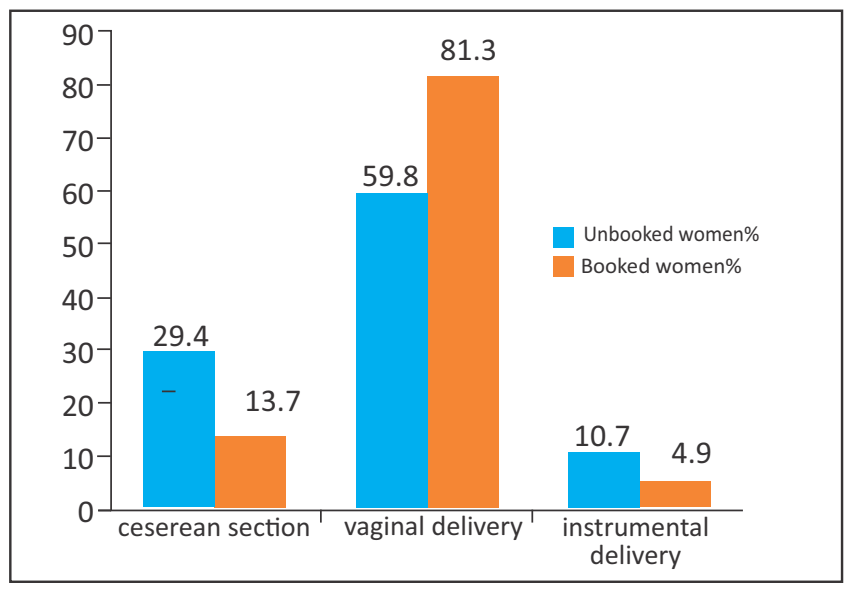

Figure 1: Mode of delivery

All the maternal morbidities and complications were more in unbooked patients including postpartum hemorrhage (12.7 $\%$ vs4.9\%) ( $p<0.05)$, preeclampsia $(9.8 \%$ vs4.9\%) $(p<0.05)$, complications of labor $(9.8 \%$ vs $1.9 \%)(p<0.05)$ and puerperal sepsis $(6.8 \%$ vs $0.98 \%)(p<0.05)$.

Out of 12 complications in labor in this study, 10 of them were in unbooked cases. Among them, 3 had obstructed labor and 7 had prolonged labor whereas in booked patients there were only 2 cases of prolonged labor. (Figure 2) 


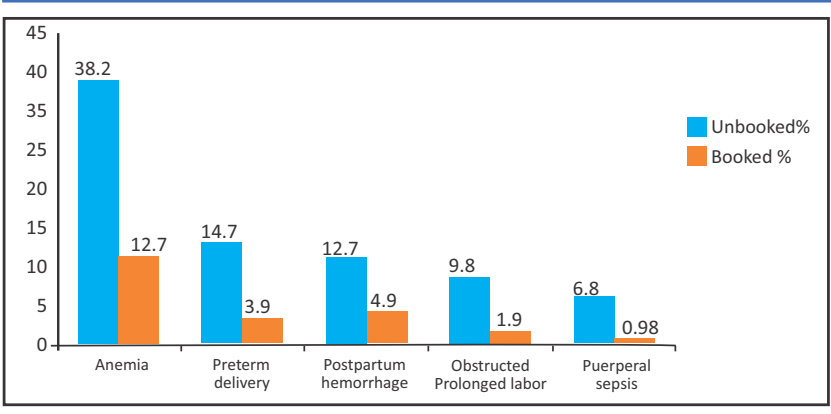

Figure 2: Complications in Mother

\begin{tabular}{|c|c|c|c|}
\hline & $\begin{array}{l}\text { Unbooked } \\
\text { women } \\
\mathbf{n}(\%)\end{array}$ & $\begin{array}{c}\text { Booked } \\
\text { women } \\
n(\%)\end{array}$ & P-Value \\
\hline \multicolumn{4}{|l|}{ Baby outcomes } \\
\hline Low birth weight ( $2500 \mathrm{gm})$ & $25(24.5)$ & $10(9.8)$ & $<0.05$ \\
\hline Mean birth weight(gm) & $2800 \pm 450$ & $3100 \pm 300$ & $<0.05$ \\
\hline Apgar score at $1 \mathrm{~min}$ & $6.56 \pm 1.12$ & $6.9 \pm 1.42$ & Not significant \\
\hline Apgar score at $5 \mathrm{~min}$ & $7.9 \pm 1.00$ & $8.4 \pm 1.4$ & Not significant \\
\hline NICU admission & $10(9.8)$ & $2(1.9)$ & $<0.05$ \\
\hline Nursery admission & $15(14.7)$ & $6(5.8)$ & $<0.05$ \\
\hline IUFD & $6(5.8)$ & $1(0.98)$ & $<0.05$ \\
\hline $\begin{array}{l}\text { Early neonatal death } \\
\text { (<7 days) }\end{array}$ & $3(2.9)$ & $1(0.98)$ & $<0.05$ \\
\hline
\end{tabular}

Fifteen patients (14.7\%) had preterm birth in unbooked cases in comparison to 4 (3.9\%) in booked cases. Unbooked patients were twice as likely to have low birth weight than booked patients $(24.5 \%$ vs9.8\%) ( $p<0.05)$. The mean birth weight was also lower in unbooked patients as compared to booked patients.

Unbooked patients had comparatively lower mean Apgar score at 1 and 5 minutes of life $(6.56 \pm 1.12$ vs $6.9 \pm 1.42)$; (7.9 \pm 1.00 vs $8.4 \pm 1.4$ ) respectively.

Out of 204 births, 33 babies were admitted and among them the majority of babies were of unbooked mothers $(24.5 \%$ vs $7.7 \%)(p<0.05)$. Overall perinatal mortality was $10.7 \%$ with $8.8 \%$ occurring in unbooked patients.

\section{DISCUSSION}

In Nepal the provision of quality antenatal care to every mother is improving. In the recent census of 2016, 84\% women had received any form of antenatal care and $70 \%$ had taken four or more ANC visits. However, still $41 \%$ of women gave birth at home. This data has clearly a lot to speak for itself as it depicts a huge gap in the trust of a pregnant mother in a health facility for delivery. ${ }^{2}$

Unfortunately, in developing countries like ours, the importance of antenatal care and its role in maternal and fetal health is still not acknowledged. In our institute where we have around 8500 deliveries a year, there are still around 700 unbooked cases (8.23\%) and this data though quite less than national data (30\%) is still alarming as this shows the void in our health system. In a study done by Owolabi et al in 2008 in Nigeria, there was 1154 deliveries in 22 months, out of which 336 (29\%) were unbooked deliveries. ${ }^{3}$

The study of sociodemographic profiles of booked and unbooked patients showed that the booking visits increase with increase in education level. Similarly, it decreases if the mother is of an extreme age group, housewife and of lower education level. Similar finding was noted in various other studies. ${ }^{4,5,6}$

In terms of mode of delivery, unbooked mothers were less likely to deliver by spontaneous vaginal delivery $(59.8 \%$ vs $81.3 \%$ ) as also seen in study by Danish et al. ${ }^{7}$ This is so as the unbooked patients come to the hospital only after problems arise so surgical intervention is likely needed for complicated labor and fetal distress. In this study, out of 14 cesarean sections done in booked patients, only 2 were emergency cases whereas in unbooked cases all the cesarean done were emergency cases. This points out the fact that in the case of a booked patient, the delivery can be planned and managed accordingly but unbooked cases have no such advantage. The percentage of cesarean section for unbooked cases in our study was $29.4 \%$. Similarly, in a study by Pokharel et $\mathrm{al}^{8}$ it was $39.8 \%$ and by Farzana et $\mathrm{al}^{9}$ it was $31.5 \%$.

Consequently, the emergency cesarean has higher complications and greater risk of puerperal sepsis as noted in our study where there were 7 cases of puerperal sepsis in unbooked cases as compared to only one in booked cases. Another factor that increases the risk of puerperal sepsis is anemia and which is seen more in unbooked cases. Many factors that lead to anemia are poverty, malnutrition and illiteracy which is characteristically seen more in unbooked cases. Due to low hemoglobin level, there is less oxygen carrying capacity of the blood so more chance of infection, hence, puerperal sepsis. ${ }^{10}$

Similarly, the incidence of postpartum hemorrhage was also more in unbooked births.Tucker et al also noted comparable findings. ${ }^{11}$

Among 15 cases of preeclampsia noted in our study, 10 were noted in unbooked patients. Similar finding of higher number of pregnancy induced hypertension was noted in unbooked patients in a study done by Tuladharet al. ${ }^{12}$ Preeclampsia, though not preventable but the severity of the progression of disease can be halted if diagnosed and treated in time. However, such opportunities are lost when the patient has no antenatal care.

None of the mothers either in booked or unbooked had mortality but among 3 cases of the obstructed labor in the unbooked case, one had postpartum hemorrhage with 3 days of ICU stay and 4 pints blood transfusion. This event visibly highlights the morbidity, financial burden that comes along with no prenatal care.

Similar to the mother, the perinatal health is also hampered by the absence of antenatal visits. Unbooked cases were also more prone to have preterm delivery $(14.7 \%$ vs $39 \%)$ and deliver low birth weight babies $(24.5 \%$ vs $9.8 \%)$. Similar findings were noted in the studies by Owolabiet al $^{3}$ and Osungbade et al. ${ }^{13}$ Increased incidence of anemia in unbooked patients could also be a risk factor for preterm delivery as noted in study done by Tucker et al. ${ }^{11}$ 
Similarly, the mean Apgar score was also low in unbooked cases. Though there were no significant differences in mean Apgar score between booked and unbooked births, but one can clearly witness the increased neonatal admission in unbooked cases which pars with increased financial burden to already poor families and hence greater perinatal mortality in unbooked patients. ${ }^{14}$

Though in this study, long term data of the babies has not been noted but various studies have shown that there is an increased risk of complications like cerebral palsy, developmental delay and long term health risks like asthma or allergies in the babies who have prolonged ICU care. ${ }^{15}$

All the complications noted in our study are preventable by proper antenatal care. Strengthening of the antenatal care and maintenance of quality care is a necessity to benefit the physical as well as mental health of the mother, baby and the whole family as documented in various studies. ${ }^{16}$

Although the Nepal government has implemented various strategies for the improvement of maternal and child health and to make antenatal care available and accessible, there is still a lack of awareness in rural eastern Nepal. Women from rural backgrounds are still clueless about the provision of the government for Free and Safe motherhood programme as well as the financial incentives given to the postpartum mother. The ministry of woman and child health should generate new ways to increase antenatal visits and reduce unbooked births to zero. Poor educational status, patriarchal society and ignorance among the women are the key factors noted in this study so focusing on female education and hence women empowerment can direct positive results.

\section{REFERENCES}

1. Lincetto O, Mothebesoane-anoh S, Gomez P, Munjanja S. Antenatal Care. World Health Organisation. :51-62.

2. Nepal 2016 Demographic and Health Survey: Key Findings. 2016.

3. Owolabi AT, Fatusi AO, Kuti O, Adeyemi A, Faturoti SO, Obiajuwa PO. Maternal complications and perinatal outcomes in booked and unbooked Nigerian mothers.Singapore medical journal. $2008 \mathrm{Jul}$ 1;49(7):526.[PubMed | Full Text | PMID]

4. Maupin R Jr, Lyman R, Fatsis J, Prystowiski E, Nguyen A, Wright C et al. Characteristics of women who deliver with no prenatal care.JMatern Fetal Neonatal Med. 2004 Jul;16(1):45-50.[PubMed | Full Text | DOI]

5. Failing F, Ripa P, Tefuarani N, Vince J. A comparison of booked and unbooked mothers delivering at the Port Moresby General Hospital : a case-control study. PNG Med J. 2004;47:174-80. [PubMed | PMID]

6. Mustard CA, Roos NP. The Relationship of Prenatal Care and Pregnancy Complications to Birthweight in Winnipeg, Canada. Am J Public Health. 1994;84(9):1450-7. [PubMed | Full Text | PMID]

7. Danish N, Fawad A, Abbasi N. Assessment of pregnancy outcome in primigravida : comparison between booked and un-booked patients. 2010;22(2):23-5. [PubMed |PMID]

8. Pokharel HP, Lama GJ, Banerjee B, Paudel LS, Pokharel PK. Maternal and perinatal outcome among the booked and unbooked pregnancies from catchments area of BP Koirala Institute of Health Sciences, Nepal. Kathmandu Univ Med J (KUMJ). 2007;5(2):173-176. [PubMed | Full Text | PMID]
There is also a stigma among people regarding delivery in hospitals as the cesarean rate in private hospitals is quite high so there is a wrong message going to the society that hospital delivery increases the risk of cesarean section. Hence, this is also one of the reasons for some people to not visit the hospital unless there is some emergency.

\section{CONCLUSIONS}

Unbooked patients in overall had high morbidity which included complicated deliveries as well as more antepartum, intrapartum and postpartum complications. Similarly, the babies from unbooked mothers also had prolonged hospital stay and ill-health.Community awareness and education is necessary to increase the number of booked patients at primary care level.

\section{RECOMMENDATION}

Increase in the antenatal visits could help to reduce the maternal and perinatal mortality and morbidity by detection of hish risk conditions in time and early intervention.

\section{ACKNOWLEDGEMENTS}

We are thankful to the nursing staff and residents of the department of Obstetrics and Gynaecologyof Nobel Medical College and Teaching hospital for helping us in carrying out this research. We are also thankful to the patients without whom this study would not have been possible.

\section{CONFLICT OF INTEREST}

There was no conflict of interest to declare.

9. Aamir F, Fasih A, Mahesh A, Charles EQ. A comparative review of maternal morbidity and perinatal outcome in booked and un-booked mothers. Pak J Surg. 2012;28(4):280-4. [Full Text]

10. Allen LH. Anemia and iron deficiency: effects on pregnancy outcome. The American journal of clinical nutrition. 2000 May 1;71(5):1280S4S. [PubMed | Full Text | DOI]

11. Tucker A, Yoong DOW, Fakokunde MNA. The unbookedmother : a cohort study of maternal and foetal outcomes in a North London Hospital. 2010;613-6. [PubMed | Full Text |DOI]

12. Tuladhar H, Dhakal N. Impact of Antenatal Care on Maternal and Perinatal utcome : A Study at Nepal Medical College Teaching Hospital. NJOG. 2011;6(2):37-43. [Full Text | DOI]

13. Osungbade KO, Ayinde OO. Birth outcomes among booked and unbooked women at a secondary health facility in southwest Nigeria: implications for strengthening perinatal health services. Journal of Child Health Care. 2011 Dec;15(4):320-8. [PubMed | Full Text | DOI]

14. Mundhra R, Singh AS, Agarwal M, Kumar R. Utilization of antenatal care and its influence on fetal-maternal outcome : a tertiary care experience. Int J Reprod Contraception, Obstet Gynecol. 2013;2(4):600-6. [IJRCOG | Full Text | DOI]

15. World Health Organization (2008) Maternal Mortality Fact Sheet. [Internet]. Available from: www.who.int/entity/making_\%0 Apregnancy _safer/events/2008/mdg5/factsheet_maternal_mortality.pdf.

16. Jong GDE, Paattison RC, Odendaal HJ. Influence of perinatal care on stillbirths in patients of low socio-economic class. SAMT. 1988;74 (16):53-4. [Full Text] 